УДК 621.391

\title{
АДАПТИВНЫЙ ВАРИАНТ ТЕХНОЛОГИИ СУРРОГАТНЫХ ДАННЫХ ДЛЯ ПОВЫШЕНИЯ ЭФФЕКТИВНОСТИ СПЕКТРАЛЬНОГО АНАЛИЗА СИГНАЛОВ СОБСТВЕННОСТРУКТУРНЫМИ МЕТОДАМИ
}

\author{
ВАСИЛИШИН В.И.
}

Харьковский университет Воздушных Сил, Украина, Харьков, 61023, ул. Сумская 77/79

\begin{abstract}
Аннотация. Рассмотрена задача повышения эффективности спектрального анализа сигналов, наблюдаемых на фоне шума, методом Root-MUSIC с использованием технологии суррогатных данных, реализованной адаптацией алгоритма рандомизации фаз отсчетов преобразования Фурье исходных данных к отношению сигнал-шум (ОСШ). Показана эффективность предложенного варианта технологии суррогатных данных при низких значениях ОСШ и малом числе выборок. При больших значениях ОСШ адаптивный вариант технологии суррогатных данных практически не приводит к появлению суррогатной помехи, характерной для неадаптивного варианта. Предложенный вариант технологии может быть применим с другими методами спектрального анализа
\end{abstract}

Ключевые слова: суррогатные данные; собственноструктурные методы

Среди современных методов спектрального анализа особое место занимают собственноструктурные (CC) методы (Писаренко, MUSIC, Root-MUSIC, ESPRIT, Min-Norm и др.), использующие собственные векторы (CB) и собственные значения (C3) корреляционной (ковариационной) матрицы наблюдений. Также эти методы называют основанными на подпространствах CB (subspace-based) [1].

Задача поиска С3 и СВ корреляционной матрицы (КМ) наблюдений также решается в разложении Карунена-Лоэва, анализе главных компонент PCA (principal component analysis), анализе независимых компонент ICA (independent component analysis), нелинейном анализе главных компонент, факторном анализе, каноническом анализе, которые получили широкое распространение в обработке сигналов, изображений [1-4].
С3 и СВ КМ входных данных, помимо методов спектрального анализа, находят применение при анализе скорости сходимости алгоритмов обработки сигналов в адаптивных антенных решетках (ААР), при оптимизации весовых коэффициентов режекторного фильтра систем селекции движущихся целей, при определении результирующей диаграммы направленности ААР через составляющие диаграммы, соответствующие СВ КМ и т.д. [1].

Использование С3 и СВ оценки априори неизвестной КМ СС методами обусловливает зависимость качества формируемых ими оценок (дисперсия, смещение) измеряемых величин (частота гармонических компонент сигнала при временном спектральном анализе, направление прихода (НП) сигналов источников излучения при пространственном спектральном анализе) от качества и свойств оценки КМ (объем используемой для оценки КМ обучаю- 